\title{
Erratum
}

\section{The predictability of large-scale wind-driven flows}

\author{
A. Mahadevan ${ }^{1, *}$, J. Lu ${ }^{2}$, S. P. Meacham ${ }^{3}$, and P. Malanotte-Rizzoli ${ }^{2}$ \\ ${ }^{1}$ Ocean Process Analysis Laboratory, University of New Hampshire, Durham, NH 03824, USA \\ * presently at: Dept. of Applied Mathematics and Theoretical Physics University of Cambridge, Silver Street, Cambridge, \\ CB3 9EW, UK \\ ${ }^{2}$ Dept. of Earth, Atmospheric and Planetary Sciences, MIT, 77 Massachusetts Avenue, Cambridge, MA 02139, USA \\ ${ }^{3}$ Atmospheric and Environmental Research, 131 Hartwell Avenue, Lexington, MA 02421, USA
}

Received: 18 September 2000 - Revised: 23 April 2001 - Accepted: 2 July 2001

Acknowledgement. A. Mahadevan, P. Malanotte-Rizolli, S. Meacham and J. Lu, the authors of "The predictability of largescale wind-driven flows" NPG, 8, 449-465, 2001, would like to thank the Office of Naval Research for their support and encouragement provided through the Directed Research Initiative on the predictability of the atmosphere and oceans. 